\title{
The Implementation and Advantages of Mixed Methods in Competitive Strategy and Management Systems
}

José F. Molina-Azorin, Juan-José Tari, María D. Lopez-Gamero, Jorge Pereira-Moliner, and Eva M. PertusaOrtega

Department of Management, University of Alicante, Alicante, Spain

\begin{abstract}
The aim of this article is to analyze the main characteristics of mixed methods research and the use of this methodological approach in several research projects and works that are being conducted by our research group about the implications and impact of management systems on competitive strategy. First, we examine the main features of mixed methods research, emphasizing why and how to use this approach. Then, we indicate our experiences as scholars who usually use mixed methods approaches in our research. We highlight the reasons and motives for using this methodology, how we conduct these studies, and the logic and key features of the mixed methods research designs that we conduct. Several implications for management research are also indicated.
\end{abstract}

\section{KEYWORDS}

Competitive strategy; environmental

management; management; mixed

methods research; quality

management; research projects

\section{Overview}

Mixed methods research involves combining qualitative and quantitative data collection and data analysis within a single study or research project. Calls for the integration of quantitative and qualitative research methods emphasizing the value and advantages of mixed methods research have been made in several fields, including sociology, education, evaluation, and the health sciences. This methodological approach is becoming increasingly articulated and recognized, alongside qualitative research and quantitative research, as the third methodological movement (Tashakkori \& Teddlie, 2003). Therefore, mixed methods research has emerged as a methodological approach with a recognized name and distinct identity (Denscombe, 2008).

Calls for the use of mixed methods research also have occurred in the management field in general (Currall \& Towler, 2003; Daft \& Lewin, 1990; Edmondson \& Mcmanus, 2007; Jick, 1979; A. S. Lee, 1991; T. W. Lee, 1999; Molina-Azorin, Bergh, Corley, \& Ketchen, 2017; Molina-Azorín \& Cameron, 2015) and in the strategic management field in particular (Armstrong \& Shimizu, 2007; Barr, 2004; Boyd, Gove, \& Hitt, 2005; Hitt, Boyd, \& Li, 2004; Hitt, Gimeno, \& Hoskisson, 1998; Molina-Azorin, 2007, 2012). For example, Hitt et al. (1998) indicated that researchers might realize the benefits and advantages of both quantitative and qualitative research approaches by integrating them into a single project. Boyd et al. (2005) pointed out that qualitative research complements quantitative research and, in tándem, quality research of both types can move the strategic management field forward more rapidly. Armstrong and Shimizu (2007) believed that using both qualitative and quantitative methods best contributes to isolating potentially unobservable resources and testing the resource-based view. Molina-Azorin (2012) conducted a systematic review of the application of mixed methods research designs in the Strategic Management Journal, examining the impact of this methodological approach in terms of citations. The findings showed that mixed methods articles tended to receive more citations than did monomethod articles.

Greene (2007) points out that mixed methods research is a way of thinking. The purpose of this article is to show our mixed methods approach and way of thinking. We are a group of scholars who conduct research in the management field, mainly about competitive strategy and sustainability practices, examining relationships with some management systems, such as quality management and environmental management. We usually adopt a mixed methods way of thinking in our works and research projects. 
In this article, we highlight the logic and contributions of using mixed methods in our research, examining why and how to implement this approach. Specifically, we indicate the benefit and key features of some studies that we are conducting, emphasizing our experience with using mixed methods, and combining and integrating qualitative and quantitative phases. Before examining these aspects, the main features of mixed methods research are briefly indicated in the next section. The framework of general mixed methods purposes and designs described in the next section will be used to examine the purposes and designs that we use in our research projects and works.

\section{Mixed Methods Research: Main Purposes and Designs}

The scientific fields with more tradition in using, studying, and developing mixed methods are education, sociology, psychology, and health sciences. Scholars from these fields have published specific books on mixed methods research (Andrew \& Halcomb, 2009; Creswell, 2015; Creswell \& Plano Clark, 2007; Greene, 2007; HesseBiber \& Johnson, 2015; Morse \& Niehaus, 2009; Plano Clark \& Creswell, 2008; Plano Clark \& Ivankova, 2016; Tashakkori \& Teddlie, 2010; Teddlie \& Tashakkori, 2009). Additionally, special issues about mixed methods have been published in journals from these fields.

Johnson, Onwuegbuzie, and Turner (2007) asked several researchers to define mixed methods and, as a result of their review, they offered a composite definition, which includes the following: Mixed methods research is the type of research in which a researcher or team of researchers combines elements of qualitative and quantitative research approaches (e.g., use of qualitative and quantitative viewpoints, data collection, analysis, inference techniques) for the broad purposes of breadth and depth of understanding and corroboration. The central premise of mixed methods research studies is that the use of quantitative and qualitative research approaches in combination may provide a better understanding of research problems and complex phenomena than does either approach alone (Creswell \& Plano Clark, 2007).

A better understanding can be obtained, for example, by triangulating one set of results with another, thereby enhancing the validity of inferences. Thus, if we use several different methods for investigating a phenomenon of interest, and the results provide mutual confirmation, we can be reassured that our results are valid (Jick, 1979). Greene, Caracelli, and Graham (1989) conceptualized the following four additional purposes: complementarity (i.e., elaboration or clarification of the results from one method with the findings from the other method), development (i.e., when the researcher uses the results from one method to help develop the utilization of the other method), expansion (i.e., seeking to extend the breadth and range of inquiry by using different methods for different inquiry components), and initiation (i.e., seeking the discovery of paradox and contradiction, new perspectives of frameworks, the recasting of questions or results from one method with questions or results from the other method). As will be indicated later, most of these purposes are addressed in our studies.

An important aspect of mixed methods research is how to use this methodological approach or, in other words, how to design and perform a mixed methods research study. Methodologists writing about mixed methods have devoted a great deal of attention to classifying the different types of mixed methods research designs. Two main factors that help researchers to design and conduct a mixed methods research study are the implementation of data collection and priority (Morgan, 1998; Morse, 1991; Tashakkori \& Teddlie, 1998). Implementation of data collection refers to the sequence the researcher uses to collect both quantitative and qualitative data. The options consist of collecting the information at the same time (i.e., concurrent, simultaneous, or parallel design) or collecting the information in phases (i.e., sequential or two-phase design). In concurrently collecting both forms of data, the researcher seeks to compare them to search for congruent findings. When the data are introduced in phases, either the qualitative or the quantitative data may be collected first, but the sequence relates to the objectives being sought by the researcher. Thus, when qualitative data collection precedes quantitative data collection, the intent may be first to explore the problem under study and then follow up on this exploration with quantitative data that are amenable to studying a large sample so that results might be inferred to a population. Alternatively, when quantitative data precede qualitative data, the intent is to test variables with a large sample and then to explore in more depth with a few cases during the qualitative phase. Regarding priority, the mixed methods researcher can give equal priority to both quantitative and qualitative research, emphasize qualitative more, or emphasize quantitative more. Mixed methods research designs, therefore, can be divided into equivalent-status designs (i.e., the researcher conducts the study using both the quantitative and the qualitative approaches approximately equally to understand the phenomenon under study) and dominant-less-dominant studies or nested designs (i.e., the researcher conducts the study within a single dominant method with a small component of the overall study drawn from an alternative design). 
These two dimensions (i.e., implementation and priority) and their possible combinations can lead to the establishment of several designs that are represented using the notation proposed by Morse (1991). In her system, the main or dominant method appears in capital letters (QUAN, QUAL), whereas the complementary method is represented by lowercase letters (quan, qual). The notation " + " is used to indicate a simultaneous design, and the arrow " $\rightarrow$ " stands for sequential design. Thus, the following four groups and nine types of mixed methods designs can exist using these two dimensions (Johnson \& Onwuegbuzie, 2004):

1) Equivalent status/simultaneous design: QUAL+QUAN.

2) Equivalent status/sequential designs: QUAL $\rightarrow$ QUAN; QUAN $\rightarrow$ QUAL.

3) Dominant/simultaneous designs: QUAL+quan; QUAN+qual.

4) Dominant/sequential designs: qual $\rightarrow$ QUAN; QUAL $\rightarrow$ quan; quan $\rightarrow$ QUAL; QUAN $\rightarrow$ qual.

There are other related classifications of mixed methods research designs, for example, triangulation, exploratory, and explanatory designs. The purpose of a triangulation mixed methods design is to simultaneously collect both quantitative and qualitative data, merge the data, and use the results to understand a research problem. The researcher collects both quantitative and qualitative data, compares results from the analysis of both data, and makes an interpretation as to whether the results from both data support or contradict each other. The triangulation design is usually a one-phase design in which researchers implement the quantitative and qualitative methods during the same timeframe and with equal weight. It generally involves the concurrent, but separate, collection and analysis of quantitative and qualitative data so that the researcher may best understand the research problem.

The purpose of an exploratory mixed methods research design is the procedure of first collecting qualitative data to explore a phenomenon, and then collecting quantitative data to explain relationships found via the qualitative data. Therefore, this design is a two-phase (sequential) mixed methods research design. In this case, the results of the first method (qualitative) can help develop or inform the second method (quantitative). This design is based on the premise that an exploration is needed for one of the following several reasons: measures or instruments are not available, the variables are unknown, or there is no guiding framework or theory. Therefore, researchers use this design when existing instruments, variables, or measures may not be known or available for the population or context under study. It is also appropriate when a researcher wants to generalize results to different groups, to test aspects of an emergent theory, or to explore a phenomenon in depth and then measure its prevalence.

The explanatory design is also a two-phase mixed methods research design, and it consists of first collecting quantitative data and then collecting qualitative data to help explain or elaborate on the quantitative results. Then, this design starts with the collection and analysis of quantitative data. The second, qualitative, phase of the study is designed so that it follows from the results of the first quantitative phase. The rationale of this approach is that the quantitative data and results provide a general picture of the research problem, but more analysis through qualitative data collection is needed to refine, extend, or explain the general picture. For example, this design is well suited to a study in which a researcher needs qualitative data to explain significant (or non-significant) results, outlier results, or surprising findings. This design also can be used when a researcher wants to form groups based on quantitative results and follow up with the groups through subsequent qualitative research, or to use quantitative participant characteristics to guide purposeful sampling for a qualitative phase. In our studies, we usually conduct sequential mixed methods research designs, both exploratory and explanatory.

\section{Our Experience: Mixed Methods Purposes and Designs in Research Projects}

As stated earlier, we would like to indicate our experience in conducting mixed methods research. Next, we describe three research projects about competitive strategy, quality management, and environmental management. We do not indicate specific results of each phase; we do delineate the major findings, and we highlight the logic, reasons, and key features of our mixed methods approach. Figure 1 shows the combination and mixed methods research designs of these three research projects.

In our first research project, we analyze the relationship among competitive strategy, quality management, and environmental management, studying the impact of quality management and environmental management on competitive advantage in the hotel industry. In order to examine this main question, we designed a mixed methods research study with three sequential phases. Specifically, following the notation indicated earlier, we used a QUAL $\rightarrow$ QUAN $\rightarrow$ QUAL design. Moreover, this three-phase design includes both exploratory and explanatory parts. The central phase of this research is the quantitative one. However, we considered appropriate to 
conduct a first exploratory qualitative phase before the quantitative phase, and also a final explanatory qualitative phase after the quantitative study for several reasons. Next, we explain these reasons and the main purposes and characteristics of this mixed methods research design.

\section{Project 1:}

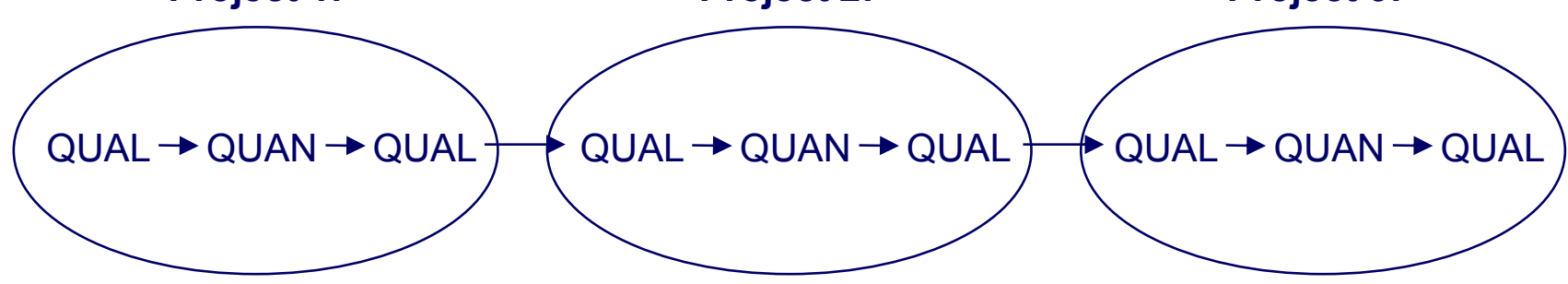

Figure 1. Mixed methods designs used in three research projects.

It was considered useful to develop an initial qualitative stage due to the inconclusive and even contradictory results found in the literature analyzing the relationships among quality management, environmental management, and competitive advantage, and also due to the need to contextualize the study within the hotel industry. The purpose of this exploratory qualitative stage was to establish some propositions in this industry context, which then were tested in the quantitative stage. Moreover, this qualitative phase also helped the development of the questionnaire used in the quantitative phase. The main technique for qualitative data collection was semistructured, in-depth interviews on various issues related to the competitive implications of quality management and environmental management in the hotel industry. A content analysis of these interviews was conducted. Mediating variables (quality performance and environmental performance) were emphasized in the 13 interviews with managers and professionals in this industry. In addition, although we do not consider a specific linkage between quality management and environmental management, managers in the hotel industry also pointed out an impact of quality management on environmental management. On the basis of these qualitative interviews and previous literature, several propositions were formulated about the impact of quality management and environmental management on competitive advantages (cost and differentiation), the mediating role of some variables, and the influence of quality management on environmental management. Thus, the main aim of this first qualitative part was development, because the results from the first qualitative phase (propositions, development of the questionnaire, context) helped develop and inform the next quantitative phase.

Several propositions were tested in the next quantitative phase. The population for this quantitative research phase included hotels located in Spain. In each hotel, the hotel manager was asked to respond to the questions related to competitive advantage, the person responsible for quality issues was asked to respond to questions on quality, and the person responsible for environmental issues was asked to respond to the questions on the environment. The statistical technique used has been structural equation modelling through partial least squares (PLS). The measurement model contained formative second-order constructs and reflective first-order constructs. More specifically, reflective constructs included operational, technical, strategic and information systems for quality and environmental management, quality performance, environmental performance, and competitive advantage regarding costs and differentiation. The consideration of formative constructs was applied to two second-order constructs: quality management and environmental management. In this way, validity was checked for the reflective and formative elements of the model. The findings showed that quality management influences cost and differentiation advantages through quality performance, environmental management impacts cost and differentiation advantages through environmental performance, and quality management impacts environmental management.

The added value and rationale of the last qualitative phase was to corroborate, analyze, elaborate, and clarify the quantitative results from the point of view of practitioners. To bridge the science-practice gap, Aguinis et al. (2010) pointed out that to demonstrate a study's practical significance, there is a need to describe quantitative results in a way that makes sense for practitioners. They suggested that this can be achieved by including practitioners in each research project as part of a qualitative research study. Therefore, these authors implicitly defend mixed methods research whereby a quantitative research study is conducted with a subsequent qualitative phase wherein managers become participants. After the application of a quantitative phase, a qualitative phase is particularly appropriate (but rare) because its goal is to understand and describe phenomena. Also, qualitative 
research gives voice to the participants and places importance on their understanding and interpretation of previous quantitative results. Therefore, we conducted new interviews ( $n=17)$ with hotel managers and other stakeholders in the hotel industry with the main mixed methods purpose of complementarity (i.e., elaboration or clarification of the quantitative results). A content analysis of these interviews was conducted. These interviews were very interesting because practitioners pointed out relevant insights about the relationships found in the quantitative phase and about the competitive importance of quality management and environmental management in the hotel industry. They corroborated the quantitative findings and, therefore, triangulation was another mixed methods purpose achieved. Moreover, they also emphasized that competitive strategy, quality management, and environmental management must go hand in hand in the hotel industry. Furthermore, they also helped to understand how quality management can influence environmental management (through specific processes and similarities). In addition, an important idea that most managers pointed out is that regarding the competitive effects of quality and environmental management, different firms can implement these management systems using varying levels of adoption and commitment. For example, they explained that some business managers use the certification of quality management and/or environmental management symbolically, without maximizing the potential of these management systems for continuous improvement. However, other firms internalize all the requirements of these systems through a full integration and adoption of these requirements in daily practices and the competitive strategy of the company.

These ideas about internalization or level of adoption of management systems indicated by some hotel managers were, in our opinion, very interesting and relevant for the fields of competitive strategy, quality management, and environmental management. And because we found limited research on the internalization of management systems, we decided to undertake further research on this topic. Therefore, this final qualitative phase provided new ideas that were used to shape a new research project.

Therefore, based on the results of this first research project, a research gap was identified regarding the internalization of management systems. These ideas led us to consider undertaking a second research project in which we analyzed the internalization of management standards in tourism organizations. Specifically, this second research project involved an examination of the relationships between motives for internalization of management standards and the internalization process, and the effects of internalization of management standards on the customer, people, society, and organizational performance in tourism organizations. In the first project, only hotels were analyzed. This second project expanded this population to the following tourist subsectors: hotels and tourist apartments, travel agencies, restaurants, rural accommodation (these four subsectors represent the group of tourist firms), and beaches and tourist information offices (these last two subsectors are classified into the group of tourist institutions).

Following the methods used in the first project, a mixed methods research study with three sequential phases was developed in this second research project that included both exploratory and explanatory phases. Therefore, again a QUAL $\rightarrow$ QUAN $\rightarrow$ QUAL design was used, taking into account that there are not only linkages among these three phases within the research project, but also between the last qualitative phase of the first research project and the first qualitative phase of this second project.

Regarding this second research project, first, a qualitative research phase was conducted due to the very few studies examining the internalization process of management standards in service organizations in existence, followed by the need to contextualize the study within the tourism organizations. The aim of this qualitative phase was to contextualize the motives for internalization, the level of internalization, and the effects of management standard internalization on performance in the six tourism subsectors previously suggested, and then to develop hypotheses and the research model. The hypotheses were proposed based on a review of the related literature and the results from this first qualitative phase. The main technique to data collection was semi-structured interviews on various issues related to the motives for internalization, internalization process, and the effects on performance in tourism organizations. Nine interviews were conducted: two interviews of managers in two Tourism Bodies, one interview of a quality consultant, three interviews of three managers in hotels, one interview of a manager in a restaurant, one interview of one person responsible for a tourist information office, and one interview of a person in charge of the beach management in a Spanish city. Based on theory and opinions expressed by the interviewers, several hypotheses were proposed about the effects of different motives for certification on the internalization dimensions, and the effects of internalization dimensions on the customer, people, society, and organizational performance. In addition, these findings helped to design a questionnaire for the next quantitative phase.

Thus, the hypotheses and the research model were tested in the second quantitative step. In this phase, a structured questionnaire with closed-ended items was sent to tourist firms in three waves. The population consists of 909 organizations that had received a quality certificate in Spain from the six subsectors indicated earlier. 
The questionnaire included items related to motives of internalization, characteristics of internalization, customer results, employee results, society results, organizational results, quality management, environmental management, environmental performance, and competitive advantage. In total, 407 completed questionnaires were received. These sets of responses were subjected to a series of structural equation models, using PLS. The results of the structural equation model revealed that 12 of the 15 hypotheses were supported for tourist firms, whereas data from the tourist institutions supported eight of the 15 hypotheses. The findings showed that internal motives are more important than external ones to facilitate internalization of management systems, that there is a relationship between internalization dimensions (continuous improvement and daily practices), and that a higher level of internalization leads to a higher level of performance.

The specific results of this quantitative research study were examined in the last qualitative phase from the point of view of practitioners. The aim of this third qualitative phase was to share our quantitative results with practitioners and to know their opinions about these quantitative findings. This knowledge would improve our understanding of these quantitative results, especially in the case of hypotheses that were not supported. Data collection was developed via a set of questions about the quantitative results, with the purpose of complementarity. These interviews helped clarify the quantitative results about the dimensions of internalization, the level of internalization, the importance of people, and the effects of internalization on outcomes. A total of 15 interviews were conducted: six quality managers in six hotels, an operation manager in a chain, a manager in a hotel, two quality managers responsible for the beach management in two city halls, a manager in a tourist information office, a quality consultant, and three managers in three Tourism Bodies. A content analysis of these interviews was conducted. Findings revealed that the respondents, in general terms, support the quantitative results, which suggested that a lack of economic resources and a continuous improvement culture can hinder internalization of management systems. They indicated that training and rewarding of employees can facilitate internalization of management systems and its influence on the performance of companies (e.g., profitability). Accordingly, a higher internalization level leads to better customer, people, society, and organizational performance. Among these qualitative results, the respondents provided relevant insights about the key role of managers and employees for a full implementation of management systems and the competitive success of these systems. These ideas help to understand how internalization can be developed and how management standards can influence company profitability.

The idea about the role of people (managers and employees) in the internalization process or the level of adoption of management systems indicated by some managers in tourism organization led us to think about the importance of human resources for the development of quality and environmental standards and, subsequently, the improvement of competitive advantage and profitability. In this context, few researchers have examined the role of individuals in the development of quality and environmental standards.

The need for new studies about the relationship among managers, employees, and the implementation of quality and environmental practices suggested that new and interesting research questions can be addressed via a new research project. Therefore, a third research project recently has been designed to address research questions related to the role of individuals (managers and employees). As with the two previous research projects, we have designed this study as a QUAL $\rightarrow$ QUAN $\rightarrow$ QUAL mixed methods research design. This design includes both exploratory and explanatory phases. The central phase of this research again will be the quantitative phase. We will conduct first an exploratory qualitative phase before the quantitative phase, and this first qualitative phase will be linked to the last qualitative phase of the second research project. Moreover, we plan to carry out a final explanatory qualitative phase after the quantitative phase.

At this moment, we are undertaking a literature review on the role of individuals in competitive strategy, quality management, and environmental management, and we have not begun any of the three phases. From a theoretical point of view, the movement of micro-foundations (Felin \& Foss, 2005; Felin, Foss, \& Ployhart, 2015) can help to include the influence of individuals in macro areas in management (where dependent and independent variables are located at the level of firm), such as strategy, quality management, and environmental management. The analysis of actions and interactions of individuals (and, thus, the level of employees within firms) supposes to consider two levels of analysis through the reciprocal influences between organizational and individual variables.

From a methodological perspective, we will combine two main methodological approaches in this third research project. Together with the mixed methods approach through three sequential phases, we will use multilevel research. Multilevel research (Klein \& Kozlowski, 2000; Mathieu \& Chen, 2011) might be an appropriate methodological approach because it helps to combine and examine relationships between variables in different levels of analysis.

At this moment, as noted earlier, we are reading works about micro-foundations and about the impact and role of individuals in strategy, quality management, and environmental management. We are also planning the 
first qualitative phase, identifying companies. We will conduct this phase mainly through interviews. The second, quantitative, phase will be conducted via a multilevel analysis. And the third and last phase, namely, the qualitative phase, as in previous research projects, will have as the main purpose to explain and clarify the quantitative findings from the perspective of practitioners. Perhaps, new ideas will emerge from this phase that will provide avenues for new research projects in the future.

\section{Implications and Recommendations}

When we started the first research project described earlier in 2009, we knew that mixed methods research was a methodological approach with a recognized name, distinct identity, and literature base. Some of our doctoral dissertations (in 2000 and 2004) involved the combination of quantitative and qualitative methods, but, at the time, we did not know that we were implementing a methodological approach called mixed methods research. We did not know the main literature base of this methodological approach and the main methodologists. We attended some of the first mixed methods research conferences held in Cambridge, and then we began to learn about this methodological approach-mainly since 2007.

Together with research projects and papers presented at conferences, we have published empirical works that involve the use of mixed methods (e.g., Molina-Azorín, Tarí, Pereira-Moliner, López-Gamero, \& Pertusa-Ortega, 2015). Also, we have published both quantitative and qualitative works. In this regard, we would like to emphasize that publishing qualitative articles and mixed methods research articles has been more difficult than publishing quantitative works.

Along with empirical works about our substantive topics in management (i.e., strategic management, quality management, and environmental management), we have conducted research on the topic of mixed methods research, conducting and publishing prevalence rate studies where we examine the application of mixed methods research in several management areas, studying the contribution and added value of using this methodological approach to help advance these areas (Molina-Azorin, 2012; Molina-Azorín \& Font, 2016; Molina-Azorín \& López-Gamero, 2016; Molina-Azorín, López-Gamero, Pereira-Moliner, \& Pertusa-Ortega, 2012).

From our experience, a significant opportunity for mixed methods research in management is its potential to examine and solve grand challenges, such as environmental degradation, climate change, poverty, health, social, and economic inequality. These challenges might call for new theories, concepts, and methods (George, 2014). Here, we think of our role as researchers and in our social responsibility to contribute to social change. For example, as we study the implementation of environmental management in companies, we think not only of the positive competitive effects that environmental management might have in firm profitability but also in the positive impact in the natural environment. Grand challenges are complex. However, mixed methods research can help address these problems because it allows scholars from diverse groups to have a common language to guide their inquiry, participants and stakeholders to be included, and policymakers in these contexts to be part of the process of problem and solution identification (Molina-Azorin et al., 2017).

These aspects are related to a significant issue in the management field, namely, the science-practice gap. Mixed methods research, as noted earlier, might contribute to addressing this shortcoming. Researchers attempt to balance the academic rigor of their studies and the practical relevance. From an academic point of view, rigor in theory development and research design is usually specified as the main indicator of the quality of a study. Yet, scholars also must consider the practical relevance of their works. Mixed methods might facilitate and enhance the interpretation of the results obtained in order to emphasize the practical implications of a study. Mixed methods may be used to understand the extent to which a study's results are significant in practice by including practitioners' discourses. In sum, the analysis of grand challenges and the practical relevance of our studies require methodological diversity. Mixed methods may play a key role because this methodological approach promotes the application of a diversity of methods, combining quantitative and qualitative approaches and using information from several different stakeholders.

We would also like to highlight our view about the relationship between research questions and methods. Our perspective is that research questions inform and are informed by methods; that is, there is a reciprocal relationship between questions and methods. Research questions influence the methods that we use, but methods also can influence the research questions that we ask. A consequence is that by extending our methodological skills, we can improve the question-asking process. By extending and sharpening our methodological skills to include different methods, we can increase the rigor of our conceptual thinking, see new ways to answer research questions, and even identify questions that would not have occurred to us otherwise (Edwards, 2008). In this regard, mixed methods research can play a vital role. Because mixed methods research involves the integration of quantitative and qualitative methods, the researcher is motivated to develop a broader set of research 
skills. Training in mixed methods can overcome the tendency to rely on known methods and play a major role in widening and extending our toolbox and repertoire of methods if the training emphasizes the importance of integrating, comparing, and mixing different methods. As indicated earlier, we attempt to extend our repertoire of methods (at this moment, in the third research project, with multilevel research).

Another important issue is how to work in research teams to undertake mixed methods research studies. Creswell (2015) points out that there is a growing presence of mixed methods research teams that consist of individuals with different methodological orientations (quantitative vs. qualitative skills), together with team members who have skills in mixed methods. These mixed methods team members may be a bridge between the quantitative and qualitative members, facilitating the conversation about differences in thinking when they appear. Mixed methods research teams should have members with a range of expertise, hold respect for diverse methodological orientations, and have a good leader who bridges across the areas of expertise and methodological orientations. The team leader ideally has experience in quantitative, qualitative, and mixed methods research. This leader also must pay attention to team composition, give equal treatment to diverse methodologies, help to shape dialogue and values and involve all team members in decisions. In our research team, there is one mixed methods team member who is the bridge between the quantitative and qualitative members.

We would also like to provide some arguments and implications related to how mixed methods research might gain legitimacy among management scholars and how the diffusion of this methodological approach can be improved. Molina-Azorin (2012) found that mixed methods research articles tended to receive more citations than did monomethod articles. Therefore, authors are advised to recognize that the use of a mixed methods research approach in their articles might help differentiate these studies from other empirical articles, and then the application of a mixed methods approach might improve the likelihood that their studies receive greater attention.

The implication for academic institutions is that the application of mixed methods research requires that management scholars develop a diversity of research capabilities. The need for such skills has implications for how researchers need to be trained. To improve the implementation of mixed methods research studies, academic institutions should increase their concern for education about this type of research. That is, along with quantitative and qualitative research courses, universities and Ph.D. programmes also should provide specific training on mixed methods. Moreover, an implication for journals is that editors should assign reviewers who have a solid understanding of mixed methods research to review manuscript submissions that involve the use of this methodological approach.

As noted earlier, other social science fields have a longer tradition of using and analysing the application of mixed methods research (mainly in education and health sciences) and, therefore, it is important to consider what management scholars could learn from their experiences. Knowledge of the literature base of mixed methods research will help management researchers to design and conduct this type of studies. Next, we discuss some recommendations regarding the application of mixed methods research. These ideas have been very useful for our studies, and we consider they can be helpful for other scholars.

Creswell (1999) presents the following nine steps for conducting a mixed methods research study, (a) determine whether a mixed methods research study is needed to study the problem, (b) consider whether a mixed methods study is feasible, (c) write both qualitative and quantitative research questions, (d) review and decide on the types of data collection, (e) assess the relative weight and implementation strategy for each method, ( $f$ ) present a visual model, (g) determine how the data will be analysed, ( $h$ ) assess the criteria for evaluating the study, and (i) develop a plan for the study. Hanson, Creswell, Plano Clark, Petska, and Creswell (2005) recommend that researchers attend closely to design and implementation issues, particularly to how and when data are collected. They also recommend that researchers familiarize themselves with the analysis and integration strategies used in the published mixed methods research studies. Moreover, in preparing a mixed methods manuscript, they recommend that researchers use the phrase mixed methods in the titles of their studies, and that, early on, researchers foreshadow the logic and progression of their studies by stating the study's purpose and research questions in the introduction. Additionally, these authors recommend that researchers explicitly state a rationale for mixing quantitative and qualitative methods and data.

Teddlie and Tashakkori (2006) point out that mixed methods research designs have an opportunistic nature. That is, in many cases, a mixed methods research study may have a predetermined research design, but new components of the design may evolve as researchers follow up on leads that develop as data are collected and analysed. Thus, a tenet of mixed methods research is that researchers should mindfully create designs that effectively answer their research questions (Johnson \& Onwuegbuzie, 2004). 


\section{Conclusion}

Mixed methods research is not the panacea for all research problems in management research. Moreover, there are several barriers to carrying out mixed methods research studies. Mixed methods studies require extensive time, resources, and effort. Mixed methods research studies are a challenge because they are perceived as requiring more work and financial resources, and they take more time. Increased time demands arise from the time necessary to implement the quantitative and qualitative parts of the study. Also, mixed methods research also requires that researchers develop a broader set of skills that span both the quantitative and the qualitative. Working as a research group (as is our case) can help to solve and cope with these issues. Another barrier is related to the challenges of publishing mixed methods research studies. The need to describe and discuss two sets of data collection, data analysis, and findings might make it difficult to publish mixed methods research studies due to the word and page restrictions that journals impose on authors.

As indicated earlier, mixed methods research is a way of thinking. The advancement of management requires an understanding and application of a variety of research methods, and mixed methods research may play a major role in this use of diverse methods. Mixed methods research shows great promise for addressing management topics and specific issues, but only if researchers understand the design options that accompany this methodological choice. Knowledge of the literature base of mixed methods research and analysis of empirical works that involve the use of a mixed methods research approach can help management researchers to design and conduct this type of studies. We hope that this article and our experience is useful for other scholars in using the potential and advantages of mixed methods research in their studies.

\section{References}

Aguinis, H., Werner, S., Abbott, J. L., Angert, C., Park, J. H., \& Kohlhausen D. (2010). Customer-centric science: Reporting significant research results with rigor, relevance, and practical impact in mind. Organizational Research Methods, 13, 515539. doi:10.1177/1094428109333339

Andrew, S., \& Halcomb E. J. (Eds.). (2009). Mixed methods research for nursing and the health sciences. Chichester, England: Wiley-Blackwell.

Armstrong, C. E., \& Shimizu, K. (2007). A review of approaches to empirical research on the resource-based view of the firm ${ }^{+}$. Journal of Management, 33, 959-986. doi:10.1177/0149206307307645

Barr, P. S. (2004). Current and potential importance of qualitative methods in strategy research. In D. J. Ketchen Jr. \& D. D. Bergh (Eds.), Research methodology in strategy and management (Vol. 1, pp. 165-188). Oxford, England: Elsevier.

Boyd, B. K., Gove, S., \& Hitt, M. A. (2005). Construct measurement in strategic management research: Illusion or reality? Strategic Management Journal, 26, 239-257. doi:10.1002/smj.444

Creswell, J. W. (1999). Mixed-method research: Introduction and application. In G. J. Cizek (Ed.), Handbook of educational policy (pp. 455-472). San Diego, CA: Academic Press.

Creswell, J. W. (2015). A concise introduction to mixed methods research. Thousand Oaks, CA: Sage.

Creswell, J. W., \& Plano Clark, V. L. (2007). Designing and conducting mixed methods research. Thousand Oaks, CA: Sage.

Currall, S. C., \& Towler, A. J. (2003). Research methods in management and organizational research: Toward integration of qualitative and quantitative techniques. In A. Tashakkori \& C. Teddlie (Eds.), Handbook of mixed methods in social and behavioral research (pp. 513-526). Thousand Oaks, CA: Sage.

Daft, R. L., \& Lewin, A. Y. (1990). Can organization studies begin to break out of the normal science straitjacket? An editorial essay. Organization Science, 1(1), 1-9. doi:10.1287/orsc.1.1.1

Denscombe, M. (2008). Communities of practice. A research paradigm for the mixed methods approach. Journal of Mixed Methods Research, 2, 270-283. doi:10.1177/1558689808316807

Edmondson, A. C., \& Mcmanus, S. E. (2007). Methodological fit in management field research. Academy of Management Review, 32, 1246-1264. doi:10.5465/AMR.2007.26586086

Edwards, J. R. (2008). To prosper, organizational psychology should ... overcome methodological barriers to progress. Journal of Organizational Behavior, 29, 469-491. doi:10.1002/job.529

Felin, T., \& Foss, N. J. (2005). Strategic organization: A field in search of micro-foundations. Strategic Organization, 3, 441455. doi:10.1177/1476127005055796

Felin, T., Foss, N. J., \& Ployhart. R. E. (2015). The microfoundations movement in strategy and organization theory. Academy of Management Annals, 9(1), 575-632. doi:10.1080/19416520.2015.1007651

George, G. (2014). From the editors: Rethinking management scholarship. Academy of Management Journal, 57(1), 1-6. doi:10.5465/amj.2014.4001

Greene, J. C. (2007). Mixed methods in social inquiry. San Francisco, CA: Jossey-Bass.

Greene, J. C., Caracelli, V. J., \& Graham, W. F. (1989). Toward a conceptual framework for mixed-method evaluation designs. Educational Evaluation and Policy Analysis, 11, 255-274. doi:10.3102/01623737011003255 
Hanson, W. E., Creswell, J. W., Plano Clark, V. L., Petska, K. S., \& Creswell, J. D. (2005). Mixed methods research designs in counseling psychology. Journal of Counseling Psychology, 52, 224-235. doi:10.1037/0022-0167.52.2.224

Hesse-Biber, S., \& Johnson, R. B. (Eds.). (2015). The Oxford handbook of multimethod and mixed methods research inquiry. Oxford, England: Oxford University Press.

Hitt, M. A., Boyd, B. K., \& Li, D. (2004). The state of strategic management research and a vision of the future. In D. J. Ketchen Jr. \& D. D. Bergh (Eds.), Research methodology in strategy and management (Vol. 1, pp. 1-31). Oxford, England: Elsevier.

Hitt, M. A., Gimeno, J., \& Hoskisson, R. E. (1998). Current and future research methods in strategic management. Organizational Research Methods, 1(1), 6-44. doi:10.1177/109442819800100103

Jick, T. D. (1979). Mixing qualitative and quantitative methods: Triangulation in action. Administrative Science Quarterly, 24, 602-611. doi:10.2307/2392366

Johnson, R. B., \& Onwuegbuzie A. J. (2004). Mixed methods research: A research paradigm whose time has come. Educational Researcher, 33(7), 14-26. doi:10.3102/0013189X033007014

Johnson, R. B., Onwuegbuzie, A. J., \& Turner, L. A. (2007). Toward a definition of mixed methods research. Journal of Mixed Methods Research, 1, 112-133. doi:10.1177/1558689806298224

Klein, K. J., \& Kozlowski, S. W. J. (Eds.). (2000). Multilevel theory, research, and methods in organizations: Foundations, extensions, and new directions. San Francisco, CA: Jossey-Bass.

Lee, A. S. (1991). Integrating positivist and interpretive approaches to organizational research. Organization Science, 2, $342-$ 365. doi:10.1287/orsc.2.4.342

Lee, T. W. (1999). Using qualitative methods in organizational research. Thousand Oaks, CA: Sage.

Mathieu, J. E., \& Chen, G. (2011). The etiology of the multilevel paradigm in management research. Journal of Management, 37, 610-641. doi:10.1177/0149206310364663

Molina-Azorin, J. F. (2007). Mixed methods in strategy research: Applications and implications in the resource-based view. In D. J. Ketchen \& D. D. Bergh (Eds.), Research methodology in strategy and management (Vol. 4, pp. 37-73). Bingley, England: Emerald Group. doi:10.1016/s1479-8387(07)04003-9

Molina-Azorin, J. F. (2012). Mixed methods research in strategic management: Impact and applications. Organizational Research Methods, 15(1), 33-56. doi:10.1177/1094428110393023

Molina-Azorin, J. F., Bergh, D. D., Corley, K. G., \& Ketchen, D. J., Jr. (2017). Mixed methods in the organizational sciences: Taking stock and moving forward. Organizational Research Methods, 20, 179-192. doi:10.1177/1094428116687026

Molina-Azorín, J. F., \& Cameron, R. (2015). History and emergent practices of multimethod and mixed methods in business research. In S. Hesse-Biber \& R. B. Johnson (Eds.), The Oxford handbook of multimethod and mixed methods research inquiry (pp. 466-485). New York, NY: Oxford University Press.

Molina-Azorín, J. F., \& Font, X. (2016). Mixed methods in sustainable tourism research: An analysis of prevalence, designs and application in JOST (2005-2014). Journal of Sustainable Tourism, 24, 549-573. doi:10.1080/09669582.2015.1073739

Molina-Azorín, J. F., \& López-Gamero, M. D. (2016). Mixed methods studies in environmental management research: Prevalence, purposes and designs. Business Strategy and the Environment, 25, 134-148. doi:10.1002/bse.1862

Molina-Azorín, J. F., López-Gamero, M. D., Pereira-Moliner, J., \& Pertusa-Ortega, E. M. (2012). Mixed methods studies in entrepreneurship research: Applications and contributions. Entrepreneurship and Regional Development, 24, 425-456. doi:10.1080/08985626.2011.603363

Molina-Azorín, J. F., Tarí, J. J., Pereira-Moliner, J., López-Gamero, M. D., \& Pertusa-Ortega, E. M. (2015). The effects of quality and environmental management on competitive advantage: A mixed methods study in the hotel industry. Tourism Management, 50, 41-54. doi:10.1016/j.tourman.2015.01.008

Morgan, D. L. (1998). Practical strategies for combining qualitative and quantitative methods: Applications to health research. Qualitative Health Research, 8, 362-376. doi:10.1177/104973239800800307

Morse, J. M. (1991). Approaches to qualitative-quantitative methodological triangulation. Nursing Research, 40, 120-123. doi:10.1097/00006199-199103000-00014

Morse, J. M., \& Niehaus, L. (2009). Mixed method design: Principles and procedures. Walnut Creek, CA: Left Coast Press.

Plano Clark, V. L., \& Creswell, J. W. (2008). The mixed methods reader. Thousand Oaks, CA: Sage.

Plano Clark, V. L., \& Ivankova, N. V. (2016). Mixed methods research. A guide to the field. Thousand Oaks, CA: Sage.

Tashakkori, A., \& Teddlie, C. (1998). Mixed methodology. Combining qualitative and quantitative approaches (Applied Social Research Methods Series Vol. 46). Thousand Oaks, CA: Sage.

Tashakkori, A., \& Teddlie C. (Eds.). (2003). Handbook of mixed methods in social and behavioral research. Thousand Oaks, CA: Sage.

Tashakkori, A., \& Teddlie C. (Eds.). (2010). Sage handbook of mixed methods in social and behavioral research (2nd ed.). Thousand Oaks, CA: Sage.

Teddlie, C., \& Tashakkori, A. (2006). A general typology of research designs featuring mixed methods. Research in the Schools, 13(1), 12-28. Retrieved from http://www.msera.org/docs/rits-v13n1-complete.pdf\#page=19

Teddlie C., \& Tashakkori A. (2009). Foundations of mixed methods research: Integrating quantitative and qualitative approaches in the social and behavioral sciences. Thousand Oaks, CA: Sage. 